\title{
Is there a role for imaging in the management of patients with diabetic foot?
}

\author{
Vartan M. Vartanians • Adolf W. Karchmer • \\ John M. Giurini • Daniel I. Rosenthal
}

Published online: 25 February 2009

(C) ISS 2009

Advanced imaging of the foot has improved our ability to evaluate the possibility of osteomyelitis. However, the ability of imaging to detect the presence of osteomyelitis does not necessarily mean that it should be used on a regular basis. Indeed, our opinion is that it is of marginal value in most patients. This is because the value of a diagnostic modality depends not only on what one needs to know but also on when one needs to know it and the level of diagnostic certainty required. Such considerations have become increasingly important in the current climate of concern over healthcare costs and the appropriate use of technology.

The infected, or potentially infected, diabetic foot can be a difficult management problem. Peripheral neuropathy can diminish symptoms and thus mask the severity of the disease. Patients often present with visible evidence of soft

V. M. Vartanians $(\bowtie)$

Department of Radiology, Massachusetts General Hospital,

25 New Chardon Street Suite 427-B,

Boston, MA 02114, USA

e-mail: vvartanians@partners.org

\section{A. W. Karchmer}

Division of Infectious Diseases,

Beth Israel Deaconess Medical Center, Harvard Medical School,

330 Brookline Ave.,

Boston, MA 02215, USA

\section{J. M. Giurini}

Division of Podiatric Surgery,

Beth Israel Deaconess Medical Center, Harvard Medical School,

One Deaconess Road,

Boston, MA 02215, USA

\section{I. Rosenthal}

Massachusetts General Hospital, Harvard Medical School,

175 Cambridge Street,

Boston, MA 02114, USA tissue infection-either ulcers or cellulitis. The presence of osteomyelitis complicates treatment and may decrease the probability of a successful outcome. Helpful clinical features that increase the probability of osteomyelitis are an ulcer with a cross-sectional area greater than $2 \mathrm{~cm}^{2}$, extending down to bone, and an ESR $>70 \mathrm{~mm} /$ hour [1]. In addition, palpation of bone in the depths of infected pedal ulcers is strongly correlated with the presence of osteomyelitis. If bone is palpated on probing, specialized imaging tests to diagnose osteomyelitis may be unnecessary [2].

Diagnostic imaging would add value if it provided increased assurance that osteomyelitis was or was not present but only if it resulted in action that otherwise would not have been taken. For example, in some diabetic patients, vascular compromise of the foot can be so severe that it overrides all other treatment considerations, making detection of osteomyelitis irrelevant. The diagnostic value of various imaging studies in diabetic foot infections has been reviewed extensively [3-6]. The attention that this subject has received in the literature reflects both the importance of the problem and the lack of consensus about how it should be handled.

It is generally accepted that radiography has poor sensitivity to the early stages of osteomyelitis $[3,7,8]$. In extreme cases, bone infection can precede radiological changes by up to 4 weeks, although in most instances changes are seen in a couple of weeks. Serial radiographs can be very persuasive if they demonstrate progressive changes of bone resorption, cortical destruction, and periosteal elevation. We are not aware of any formal evaluations of the role of serial radiographs in the diagnosis of osteomyelitis.

In addition, radiographic interpretation may be complicated by other clinical conditions often found in diabetic patients including both gout and Charcot osteoarthropathy 
[9]. The limitations of radiography have led to a search for other imaging techniques. One of the first and still most commonly used techniques is the radionuclide bone scan. However, severe vascular compromise may impair the usefulness of any diagnostic tests that depend upon blood flow, including both isotope scans and contrast-enhanced magnetic resonance imaging (MRI) $[10,11]$.

The sensitivity of a 3- (or 4) phase bisphosphonatelinked technetium bone scan is certainly greater than that of radiography in early osteomyelitis. In 1995, Eckman et al. [4] calculated a weighted average for diagnostic sensitivity for published studies of $86 \%$; more recent studies report values from $50 \%$ [7] to $83 \%$ [8]. Specificity, however, is poor [7, 8] (averaging 50\%) because almost any type of bone disorder (including neuroarthropathy and healing osteomyelitis) can cause increased isotope uptake on a bone scan. For this reason, some authorities have concluded that positive technetium bone scans do not increase the probability of disease very much and negative ones do not decrease it very much, and therefore, this modality should be used infrequently [12].

Other radionuclide imaging agents - for example, scans that use white blood cells (labeled autologous leukocytes), labeled immunoglobulin, or other infection-specific radiopharmaceuticals - are more specific than the technetium bone scan $[6,13,14]$. The sensitivity of these tests can be limited in some situations [7]. They can be helpful in distinguishing osteomyelitis from soft tissue infection or Charcot-type changes [15]. However, they lack spatial resolution, are expensive and technically demanding, and should be viewed as special-purpose problem solving tools rather than either first or second line modalities.

Positron emission tomography (PET) imaging has shown promise. One authority believes that PET has the highest overall accuracy [16]. However, it is among the most expensive of the diagnostic modalities, and availability, although rapidly increasing, is still limited. In addition, new modalities tend to be enthusiastically received, with subsequent studies revealing deficiencies. At least one recent publication did not find the quality of the PET data sufficiently persuasive to draw conclusions [17].

Most clinicians agree that MRI is the most useful of the newer clinical imaging tools. The characteristic MRI changes of early osteomyelitis are caused by marrow edema associated with inflammation. These features result in low signal on T1-weighted images, high signal intensity on T2-weighted images, and contrast (gadolinium) enhancement. They may occur before there is bone destruction and account for the increased sensitivity of MRI compared to radiographic techniques [radiography or computed tomography (CT)]. Diagnostic sensitivity for osteomyelitis has generally been reported to be $90-100 \%$ $[4,7,8,18]$.

Specificity is more problematic if marrow edema is used as the primary diagnostic criterion. Many conditions other than osteomyelitis may cause marrow edema, including "overuse syndromes" [19, 20], gout, and neuropathic osteoarthropathy [18]. Most importantly, inflammation of adjacent soft tissue due to cellulitis or ulcer may result in edema of the adjacent bone. As a result, some studies have shown overall MRI specificity to be as low as 60\% [16] and even lower in some anatomical locations and in the presence of Charcot Arthropathy [21].

It has been suggested that the pattern of marrow edema can be used to distinguish between reactive marrow changes and infections. Osteomyelitis was said to be clinically present when there was confluent, geographic $\mathrm{T} 1$ signal decrease in concordance with $\mathrm{T} 2$ changes and T1 contrast enhancement, but not when the T1 signal was hazy-reticulated (edema) or subcortical (reactive), regardless of T2 pattern or enhancement. This emphasizes the importance of morphological features rather than signal

Table 1 Posttest probability stratified by imaging test result across a spectrum of pretest probabilities

\begin{tabular}{lcccc}
\hline Pretest probability (\%) & \multicolumn{3}{l}{ Post-test probability (\%) } \\
\cline { 2 - 4 } & MRI positive $^{\mathrm{a}}$ & MRI negative & Technetium Tc 99m positive $^{\mathrm{b}}$ & Technetium Tc 99m negative \\
\hline 10.0 & 36.2 & 1.3 & 11.2 & 3.4 \\
25.0 & 63.0 & 3.8 & 27.4 & 9.6 \\
50.0 & 83.6 & 10.7 & 53.1 & 24.2 \\
75.0 & 93.9 & 26.5 & 77.2 & 49.0 \\
90.0 & 97.9 & 51.9 & 91.1 & 74.2 \\
\hline
\end{tabular}

Reproduced from reference [12] with the publisher's permission

${ }^{\text {a } U s i n g ~ a l l-s t u d i e s ~ e s t i m a t e, ~ w h i c h ~ w a s ~ l o w e r ~ t h a n ~ t h a t ~ c a l c u l a t e d ~ f r o m ~ s t u d i e s ~ t h a t ~ a l s o ~ h a d ~ t e c h n e t i u m ~ T c ~} 99 \mathrm{~m}$ data. The $90 \%$ sensitivity and $82.5 \%$ specificity translate to a positive likelihood ratio of 5.1 and a negative likelihood ratio of 0.12

${ }^{\mathrm{b}}$ Using a higher sensitivity threshold of $95 \%$, which decreases the negative likelihood ratio to 0.32 ; the specificity at this threshold is $16 \%$ and the positive likelihood ratio is 1.13 
characteristics in identifying osteomyelitis and introduces an undesirable subjective element [22]. The role of contrast enhancement is unclear. Some authorities believe that contrast enhancement is "extremely useful" [23]. Unfortunately, contrast is contraindicated in diabetic patients with renal impairment due to the risk of systemic fibrosis. In addition, tissue devitalized by ischemia may show confusing patterns of contrast uptake, and neuroarthropathy may closely mimic osteomyelitis [23].

Therefore, interpretation of MRI scans is subject to numerous caveats. Some of these may arise from the fact that the trials to evaluate the role of imaging tend to have extraordinarily high prevalence of disease. Most studies of the diagnostic usefulness of imaging for osteomyelitis have been performed in patients selected on the grounds of clinical suspicion, resulting in major selection bias [24]. One analysis of 17 publications selected for overall quality reported an average pre-test probability of disease of 55\% [12]! This type of selection bias tends to overvalue a diagnostic test. Because of this, published positive and negative predictive values as high as $93 \%$ and $100 \%$ should be viewed with some skepticism [8]. In the context of a $50 \%$ pre-test probability of disease and accepting the published sensitivity and specificity of MRI, a positive examination would increase the probability of osteomyelitis to $84 \%$, but with a pre-test probability of only $10 \%$, a positive MRI increases the probability of disease to $36 \%$, a level of confidence that is not high enough for decision making [12]. (Table 1)

Does any of this affect clinical decision making? If there is severe bone destruction, as demonstrated on radiographs, surgical intervention is often needed to remove sequestrae, as well as to remodel weight bearing and thus prevent future repeat ulceration. In such cases, MRI is not required for diagnosis. For less advanced cases, MRI may be the only imaging modality with enough sensitivity to detect change. However, in such instances, a trial of antibiotic therapy may be warranted. Although traditional wisdom has been that osteomyelitis requires surgical intervention, improvements in antibiotic therapy may have changed this. There is increased confidence in the safety of clindamycin and other potent antibiotics and greater confidence in the long-term tolerance of oral therapy. These factors have lead to an increasing number of reports of the successful treatment of osteomyelitis with oral medication [25].

Since medical therapy for soft tissue infection commonly extends over several weeks, there is adequate time for radiographic changes of osteomyelitis to develop. If no radiographic changes are visible in the bone after 2 or 3 weeks, our experience indicates that osteomyelitis can be confidently excluded. In such instances, the MRI is unnecessary. It must be admitted, however, that we are not aware of any studies of the value of serial radiographs to diagnose osteomyelitis.
Detection of an unsuspected abscess might alter the early phases of treatment, but this is a very rare event, as the foot is easily accessible to physical examination, particularly in the setting of pain insensitivity due to severe neuropathy as noted in these patients. In addition, there is also reason to suspect that the imaging features of infection may not be useful in predicting the outcome of medical therapy. In the case of spinal infection, Zarrouk et al. showed that imaging abnormalities including edema, epidural abscess, disc abscess, and paravertebral abscess did not predict the outcome of treatment. Persistent findings did not predict an unfavorable clinical outcome and were not associated with relapses, neurological sequelae, or persistent pain [26].

Eckman et al. [4] have used cost-effectiveness modeling techniques to support the concept that imaging other than radiography is not justified on a routine basis. Although the assumptions they used in the model have been disputed [3], we agree with Eckman.

The diagnosis and treatment guidelines of the Infectious Diseases Society of America [27] recommend empirical treatment for 2-4 weeks. Radiographs of the foot are included in the pathway; however, if the patient is not sick enough to require hospitalization, no other imaging is recommended, even if the patient does not respond well to therapy. If the patient is very ill and requires hospitalization, then the guidelines state that advanced imaging such as CT, MRI, and bone scan should be considered, as these modalities may be helpful for surgical planning [27].

In summary, we believe that imaging has a limited role in the management of patients with diabetic foot problems. In rare cases, it may play a role in surgical planning, but it should seldom be required for diagnosis.

\section{References}

1. Butalia S, Palda VA, Sargeant RJ, Detsky AS, Mourad O. Does this patient with diabetes have osteomyelitis of the lower extremity? JAMA 2008;299(7): 806-813.

2. Grayson ML, Gibbons GW, Balogh K, Levin E, Karchmer AW. Probing to bone in infected pedal ulcers. A clinical sign of underlying osteomyelitis in diabetic patients. JAMA 1995;273(9): 721-723.

3. Lipsky BA. Osteomyelitis of the foot in diabetic patients. Clin Infect Dis 1997;25(6): 1318-1326.

4. Eckman MH, Greenfield S, Mackey WC, Wong JB, Kaplan S, Sullivan L, et al. Foot infections in diabetic patients. Decision and cost-effectiveness analyses. JAMA 1995;273(9): 712-720.

5. Tomas MB, Patel M, Marwin SE, Palestro CJ. The diabetic foot. Br J Radiol 2000;73(868): 443-450.

6. Becker W. Imaging osteomyelitis and the diabetic foot. Q J Nucl Med 1999;43(1): 9-20.

7. Croll SD, Nicholas GG, Osborne MA, Wasser TE, Jones S. Role of magnetic resonance imaging in the diagnosis of osteomyelitis in diabetic foot infections. J Vasc Surg 1996;24(2): 266-270.

8. Enderle MD, Coerper S, Schweizer HP, Kopp AE, Thelen MH, Meisner $\mathrm{C}$, et al. Correlation of imaging techniques to histopa- 
thology in patients with diabetic foot syndrome and clinical suspicion of chronic osteomyelitis. The role of high-resolution ultrasound. Diabetes Care 1999;22(2): 294-299.

9. Rajbhandari SM, Jenkins RC, Davies C, Tesfaye S. Charcot neuroarthropathy in diabetes mellitus. Diabetologia 2002;45(8): 1085-1096.

10. Yuh WT, Corson JD, Baraniewski HM, Rezai K, Shamma AR, Kathol MH, et al. Osteomyelitis of the foot in diabetic patients: evaluation with plain film, 99mTc-MDP bone scintigraphy, and MR imaging. AJR Am J Roentgenol 1989;152(4): 795-800.

11. Larcos G, Brown ML, Sutton RT. Diagnosis of osteomyelitis of the foot in diabetic patients: value of 111 In-leukocyte scintigraphy. AJR Am J Roentgenol 1991;157(3): 527-531.

12. Kapoor A, Page S, Lavalley M, Gale DR, Felson DT. Magnetic resonance imaging for diagnosing foot osteomyelitis: a metaanalysis. Arch Intern Med 2007;167(2): 125-132.

13. Harwood SJ, Valdivia S, Hung GL, Quenzer RW. Use of Sulesomab, a radiolabeled antibody fragment, to detect osteomyelitis in diabetic patients with foot ulcers by leukoscintigraphy. Clin Infect Dis 1999;28(6): 1200-1205.

14. Gross MD, Shapiro B, Fig LM, Steventon R, Skinner RW, Hay RV. Imaging of human infection with (131)I-labeled recombinant human interleukin-8. J Nucl Med 2001;42(11): 1656-1659.

15. Unal SN, Birinci H, Baktiroglu S, Cantez S. Comparison of Tc$99 \mathrm{~m}$ methylene diphosphonate, Tc-99m human immune globulin, and Tc-99m-labeled white blood cell scintigraphy in the diabetic foot. Clin Nucl Med 2001;26(12): 1016-1021.

16. Termaat MF, Raijmakers PG, Scholten HJ, Bakker FC, Patka P, Haarman HJ. The accuracy of diagnostic imaging for the assessment of chronic osteomyelitis: a systematic review and meta-analysis. J Bone Jt Surg Am 2005;87(11): 2464-2471.

17. Dinh MT, Abad CL, Safdar N. Diagnostic accuracy of the physical examination and imaging tests for osteomyelitis under- lying diabetic foot ulcers: meta-analysis. Clin Infect Dis 2008;47 (4): 519-527.

18. Craig JG, Amin MB, Wu K, Eyler WR, van Holsbeeck MT, Bouffard JA, et al. Osteomyelitis of the diabetic foot: MR imagingpathologic correlation. Radiology 1997;203(3): 849-855.

19. Lohman M, Kivisaari A, Vehmas T, Kallio P, Malmivaara A, Kivisaari L. MRI abnormalities of foot and ankle in asymptomatic, physically active individuals. Skelet Radiol 2001;30(2): 6166.

20. Zanetti M, Steiner CL, Seifert B, Hodler J. Clinical outcome of edema-like bone marrow abnormalities of the foot. Radiology 2002;222(1): 184-188.

21. Lipman BT, Collier BD, Carrera GF, Timins ME, Erickson SJ, Johnson JE, et al. Detection of osteomyelitis in the neuropathic foot: nuclear medicine, MRI and conventional radiography. Clin Nucl Med 1998;23(2): 77-82.

22. Collins MS, Schaar MM, Wenger DE, Mandrekar JN. T1weighted MRI characteristics of pedal osteomyelitis. AJR Am J Roentgenol 2005;185(2): 386-393.

23. Chatha DS, Cunningham PM, Schweitzer ME. MR imaging of the diabetic foot: diagnostic challenges. Radiol Clin North Am. 2005;43(4): 747-759.

24. Wrobel JS, Connolly JE. Making the diagnosis of osteomyelitis. The role of prevalence. J Am Podiatr Med Assoc 1998;88(7): 337-343.

25. Jeffcoate WJ, Lipsky BA. Controversies in diagnosing and managing osteomyelitis of the foot in diabetes. Clin Infect Dis 2004;39(Suppl 2): S115-S122.

26. Zarrouk V, Feydy A, Salles F, Dufour V, Guigui P, Redondo A, et al. Imaging does not predict the clinical outcome of bacterial vertebral osteomyelitis. Rheumatology (Oxford) 2007;46(2): 292295.

27. Lipsky BA, Berendt AR, Deery HG, Embil JM, Joseph WS, Karchmer AW, et al. Diagnosis and treatment of diabetic foot infections. Clin Infect Dis. 2004;39(7): 885-910. 